\title{
SELF-REPRESENTATION IN ENGLISH SPOKEN DISCOURSE: CORPUS-BASED PRAGMATIC-AND-SOCIOLINGUISTIC APPROACH
}

\author{
Elena Yu. Ilyinova \\ Volgograd State University, Volgograd, Russia \\ Larisa A. Kochetova \\ Volgograd State University, Volgograd, Russia
}

\begin{abstract}
The paper is devoted to a corpus-based pragmatic-social-and-linguistic analysis of the tag clause that is considered to be a form of discursive self-representation. Reflecting such social conventions of Britishness as distance regulation and communicative tonality of the tag clause is used in coordination with social status and a speaker's role in interactions. The research is based on oral speech samples from the British National Corpus. Social, demographic, regional, age and some other metadata of the corpus were supported by Lancaster Stats Tools online, which helped to integrate statistics on the frequency of tag clause usage, to characterize its syntactic variations and discourse value in English oral talks. Three syntactic models that differ in their predicative base may be used in English to construct the tag clause (affirmative, interrogative, imperative), and their choice reflects the varieties of pragmatic intentions, that may be: fact or detail verification, small talk, strong or weak position representation, consent, agreement or objection, disagreement, disbelief, disregard, or politeness. Corpus analysis of social indexes of speakers points to low level of gender preferences in the tag clause usage, proves correlation between various intentions of self-representation and the choice of tag clause models by social classes and age groups on a synchrony level, highlights negative dynamics in the frequency of tag clause in speech of modern young British.

Key words: discourse, corpus, corpus-based methodology, self-representation, sociolinguistic approach.

Citation. Ilyinova E.Yu., Kochetova L.A. Self-Representation in English Spoken Discourse: Corpus-Based Pragmatic-and-Sociolinguistic Approach. Vestnik Volgogradskogo gosudarstvennogo universiteta. Seriya 2, Yazykoznanie [Science Journal of Volgograd State University. Linguistics], 2018, vol. 17, no. 3, pp. 35-48. (in Russian). DOI: https://doi.org/10.15688/jvolsu2.2018.3.4
\end{abstract}

\section{ДИСКУРСИВНАЯ САМОРЕПРЕЗЕНТАЦИЯ ЛИЧНОСТИ В АНГЛОЯЗЫЧНОМ МЕЖЛИЧНОСТНОМ ОБЩЕНИИ: КОРПУСНЫЙ ПРАГМАСОЦИОЛИНГВИСТИЧЕСКИЙ АНАЛИЗ}

\author{
Елена Юрьевна Ильинова \\ Волгоградский государственный университет, г. Волгоград, Россия \\ Лариса Анатольевна Кочетова \\ Волгоградский государственный университет, г. Волгоград, Россия
}

Аннотация. В статье предлагается корпусно-ориентированный прагмасоциолингвистический анализ разделительного предложения, которое рассматривается как одна из форм дискурсивной саморепрезентации личности, отражающая своеобразие такой конвенции англоязычного межличностного общения, как 
дистанцирование и интонирование вербальных действий с учетом социального и ролевого статуса личности. Материалом исследования послужили фрагменты устного общения, зафиксированные в Британском национальном корпусе. Социально-демографические, региональные, возрастные и иные метаданные корпуса в сочетании с программными возможностями извлечения и статистической обработки информации о частотности использования форм разделительного предложения в устном общении позволили представить объективные данные о синтаксических вариантах и дискурсивной ценности исследуемой формы речи для англоязычной коммуникации. Разделительное предложение формируется в английском языке по трем синтаксическим моделям, формально различающимся по структуре предикативной базы (утвердительная, вопросительная, императивная основы), что отражает разнообразие прагматических задач коммуниканта: уточнить факты и детали, поддержать разговор, продемонстрировать сильную или слабую позицию в коммуникации, выразить согласие или несогласие, сомнение, уважение, презрение и пр. Изучение социолингвистических характеристик с опорой на методы корпусного анализа позволило доказать низкий уровень гендерной зависимости при выборе разделительного предложения для саморепрезентации личности в общении, установить корреляции между функцией саморепрезентации и формами разделительного предложения для разных социальных и возрастных групп на синхронном уровне, выявить в диахронном сравнении динамику снижения частотности использования данной формы речи представителями молодого поколения современных британцев.

Ключевые слова: дискурс, корпус, корпусная методология, саморепрезентация, социолингвистический подход.

Цитирование. Ильинова Е. Ю., Кочетова Л. А. Дискурсивная саморепрезентация личности в англоязычном межличностном общении: корпусный прагмасоциолингвистический анализ // Вестник Волгоградского государственного университета. Серия 2, Языкознание. - 2018. - T. 17, № 3. - С. 35-48. - DOI: https:// doi.org/10.15688/jvolsu2.2018.3.4

\section{Введение}

Поиск возможностей системного представления репрезентации языковой личности в коммуникативной практике входит в число актуальных задач отечественной дискурсивной лингвистики. Опираясь на общие положения теории дискурса, исследователи фокусируют внимание на научном анализе такого объекта, как дискурсивная личность, включенная в типовые бытовые коммуникативные ситуации, а предметом избирают типы общения, выделяемые с учетом социально-ролевого статуса участников и цели коммуникации, рассматривают и собственно коммуникативные действия, погруженные в условия национально специфичного сценария общения [Ирисханова, 2009; Карасик, 2014; Матвеева, Ленец, Петрова, 2013; Почтарь, 2014 ; Plotnikova, 2013 и др.]. Отметим, что в работах отечественных авторов активно обсуждаются методики описания дискурса как «личностно, культурно и ситуативно детерминированной коммуникативной практики» [Карасик, 2014 , с. 146]. Исследователей интересуют общие процессы текстопорожения и текстовосприятия, их соотношение, типы коммуникативных действий в контексте «тех задач, которые решаются человеком по мере осуществления им речевых актов, разных по своим установкам и целям, по условиям их осуществления» [Кубрякова, 2004, с. 519-520], а также конвенции вербальных действий, обусловленные социолингвистической, национально-культурной, стилевой и тональной спецификой общения [Волкова, 2014; Карасик, 2014; Литвинова, 2015; Моторина, 2013; Atai, Sadr, 2008; Boncea, 2013; English Language..., 2018; Spencer-Oatey, 2000; Stubbs, 1983; Yang, 2013 и др.]. При этом общая тенденция, нацеленная на преодоление условных границ между лингвопрагматическим, когнитивно-семантическим и социокультурным подходами к изучению дискурса в его разных реализациях, дополняется методами корпусной лингвистики, внедряемыми в исследования, посвященные изучению разных форм вербальных действий [Чернявская, 2018; Baker, 2006; Brezina, 2018; Partington, 2010 и др.]. В частности, активное развитие корпусной лингвистики и формирование электронных корпусов текстов и устной речи открывают сегодня возможности для получения объективных данных об общих и вариативных моделях дискурсивных практик в разных коммуникативных ситуациях и с учетом заданных исследователем со- 
циальных, прагматических, иных параметров, определяющих природу дискурса как «исторически сложившейся опосредованной языком формы социальной практики» [Историческая динамика дискурсивных практик, 2017, с. 5].

В данной работе представлена концепция изучения динамики некоторых приемов дискурсивной саморепрезентации личности в социолингвистическом аспекте, основанная на методах корпусной лингвистики.

\section{Дискурсивность саморепрезентации личности в англоязычном межличностном общении}

Представление о саморепрезентации личности в коммуникации соотносится с общим определением дискурсивной личности как типажа коммуниканта, «выделяемого на основании социолингвистических характеристик личностно либо статусно обусловленного общения» [Карасик, 2014, с. 182]. По мнению В.И. Карасика, дискурсивная личность проявляется в типовых формах коммуникативного поведения, которые могут быть описаны по признакам ситуативной и тематической отнесенности предмета речи, оценочного отношения к действительности или партнеру, стилистике и тональности речи [Карасик, 2014, с. 183]. Представляется, что в данном случае можно говорить о металингвистической дискурсивности или паттернах речемыслительной деятельности, характерных для личностно-ориентированной или социальноориентированной коммуникативной практики. При этом коммуникативные поступки личности опираются на общие и национально-специфические конвенции межличностного общения, а их проявлением можно считать разновидности вербальных действий, выбор которых обусловлен социальным и прагматическим модусами общения, коммуникативным контекстом. Социальный аспект предполагает детальное описание фона коммуникации, разбор социальных и ролевых признаков коммуникантов, уточнение природы их влияния на речевую практику. Указывая на значимость фактора прагматики общения, мы подчеркиваем необходимость анализа металингвистических особенностей коммуникативной ситуации с учетом параметров перформатив- ности высказываний, коммуникативного стиля и тональности общения.

Полагаем, что анализ речевого поведения дискурсивной личности с учетом разных индикаторов речевого поведения, проведенный на корпусном материале, открывает путь для выявления типичных предикативных моделей речи, проведения ранжирования вербальных действий с поправкой на социальноролевой статус каждого участника коммуникативной ситуации. Иными словами, многоаспектный метадискурсивный анализ с опорой на достоверные корпусные данные о специфике перформативности речевой практики личности позволяет соотнести ее (личности) речевые поступки с общими и частными прагматическими задачами коммуникации, установив при этом приемы языковой саморепрезентации личности в границах определенного типа дискурса.

В фокусе данного исследования находится такой способ дискурсивной саморепрезентации личности в обычном бытовом общении, как использование разделительного вопроса. Он, по мнению многих специалистов, отражает национально-культурную специфику межличностных отношений в британской модели общения [Ларина, 2009; Fox, 2004; Pearson, West, Turner, 2005 и др.]. Однако подобные утверждения в значительной степени гипотетичны, поскольку они, по нашим сведениям, не получили серьезной лингвистической проверки.

Языковая сущность данной сложной синтаксической структуры высказывания, аттестуемой в грамматике английского языка как tag question, детально описана в аспектах структуры и общекатегориальной семантики. С точки зрения структуры оно состоит из двух логических компонентов - базового предложения и синтаксического присоединения, называемого присоединительным вопросительным предложением [Иванова, Бурлакова, Почепцов, 1981, с. 180] или clause tag [Downing, 2015, p. 123-124]. В английском языке в качестве предикативной базы могут использоваться повествовательные, восклицательные, повелительные структуры, например, He drank, didn't he?, You didn't think of that, did you? (declarative base), How nice it was there, wasn't it? (exclamative base); Tell him, Christopher, will you? (imperative base). Вторая часть пред- 
ложения (clause tag) - это минимальная предикативная структура, состоящая из оперативного сказуемого (позитивной или негативной формы вспомогательных глаголов $d o$, have, be, некоторых модальных глаголов) и личного местоимения, замещающего семантическую составляющую субъекта в позиции подлежащего.

Данная модель разделительного вопросительного предложения активно используется в ходе коммуникативных интеракций для уточнения фактов, поддержания разговора, демонстрации согласия / несогласия, сомнения, но она не считается полностью независимой. С точки зрения общей коммуникативной задачи такие предложения указывают на интенцию «запроса о реальности, выраженной в предикативной связи» по отношению к утвердительной части предложения [Иванова, 1981, с. 180], при этом у носителей английского языка есть два варианта построения подобного предложения, различающихся по признаку контрастности предикативной составляющей высказывания. В соответствии с грамматической конвенцией британского варианта английского языка требуется выбирать отрицательную форму $t a g$, если базовое предложение получило позитивную предикативную форму, и наоборот, например: He is Harry Kane, isn't he? He isn't with Harry Kane, is he? [Quirk et al., 1985, p. 810]. Грамматические правила английского языка допускают некоторую вариативность в расположении clause tag, в частности, основной считается финальная позиция (You've lost the money, have you?), но в отдельных случаях встречаются иные локации (напр., It's easy, isn't it, to get used to this new style?).

Полагая, что в целом сведения о структуре и категориальной семантике разделительного вопросительного предложения (далее - РВП) общеизвестны, перейдем к размышлениям о прагматическом аспекте его частого включения в англоязычную коммуникативную практику и о социально-ролевом фоне, влияющем на выбор формы исследуемой нами предикативной модели предложения. Несмотря на долговременный интерес к прагматическому назначению РВП в данном аспекте, оно представляется мало изученным. Знакомство с работами зарубежных и отечественных спе- циалистов по грамматике и прагматике английского языка свидетельствует о наличии самых поверхностных выводов о значимости изучаемой единицы языка для коммуникативного взаимодействия. Так, отечественные специалисты по грамматике английского языка отмечали, что РВП в силу смысловой контрастности частей придает выразительность и утверждению, и вопросу (см., например: [Иванова, 1981, с. 180]). В публикациях зарубежных авторов представлены данные о вариативности построения предикативной структуры РВП и приведены авторские гипотезы о социокультурном и прагматическом фоне (контексте) их употребления в речи. В частности, первые наблюдения о роли РВП были зафиксированы в публикациях Р. Лакофф, где она указала на тональность прагматической неопределенности, которую придает разговоpy РВП: «So a tag-question is really intermediate between a statement and a question: a statement assumes that the addressee will agree, and a question leaves the response of the addressee up to him, but a tag-question implies that, while the speaker expects a certain sort of response, the hearer may not provide it» [Lakoff, 2017, p. 21]. В книге А. Даунинг описание вариантов образования РВП сопровождается рядом комментариев. Во-первых, если структурно повествовательная модель основы точно следует грамматическому предписанию о полярности предикативной составляющей предложения, то в аспекте коммуникативной тональности допустима вариативность по модусу модальности - произнесение tags с восходящей интонацией следует воспринимать как выражение сомнения, призыв для подтверждения ( $\mathrm{Am} I$ right?), нисходящая интонация отражает уверенность говорящего в правильности высказанного и ожидание подтверждения, согласия со стороны партнера (I'm asking you to confirm this; I am seeking for agreement) [Downing, 2015, p. 123-124]. Во-вторых, в англоязычной речевой практике выявляются варианты РВП с нулевой полярностью, что представлено, в первую очередь, в сочетании повествовательных предложений, чаще утверждений, с позитивным знаком в вопросительной части. Такие высказывания характеризуются наличием дискурсивных слов $\mathrm{Oh}$, So, Well now, которые указывают на дополнитель- 
ную прагматическую интенцию говорящего придать своему высказыванию вид фразы, завершающей обсуждение, взять на себя право подводить итоги беседы, делать выводы, например: So, that's what they call them now, don't they?. Они также могут передавать знаки эмоциональной импликатуры (выражать удивление: Oh, so уои are our new assistant, are you?; передавать негативное отношение: Well, I reckon so that's what she said about $m e$, is it?). В-третьих, в речевой практике выделяются варианты с полным рассогласованием правила полярности частей РВП. Такие случаи связаны с намерением продемонстрировать интерес к высказыванию партнера (например, interest, involvement). Так, в следующей ситуации на реплику шофера такси I think I've lost my way может последовать такая реакция пассажира Have you?, при этом в американской интеракции это может быть You do? You have? [Downing, 2015, p. 124]). А. Даунинг указывает и на гендерную специфику подобных форм РВП. Полное рассогласование правил полярности предикации и замещение референта в позиции подлежащего в высказывании Ooh! I love squirrels, don't you?, по мнению исследователя, свидетельствует о женской манере общения, связанной со стремлением поддерживать гармоничную тональность интеракции. Наряду с вышеуказанными вариантами использования моделей РВП с разными знаками полярности в зоне предикации в речевой практике наблюдается активная реализация композиционно усложненных моделей РВП. Они дополнены инициальными фразами I think, I consider, I reckon, I suppose, призванные внести в общение тональность отстраненности от высказываемого утверждения, например: I think, he left before lunch, didn't he?

Приведенные наблюдения о семантических особенностях модели РВП и ее прагматической ценности отличаются обобщенностью и требуют верификации. В частности, можно подвергнуть сомнению утверждения о гендерной прагматике РВП, на которые обратили внимание некоторые социолингвисты в прошлом веке. Так, следуя мнению Р. Лакофф [Lakoff, 1972], Г. Юль указал на очевидные различия в тактиках женского и мужского речевого поведения, выраженные, в том числе, в обращении к РВП: «They are used more often by women when expressing opinions. These features of women's speech all seem to be ways of inviting agreement with an idea rather than asserting it. Men tend to use more assertive forms and 'strong' language» [Yule, 2006, p. 224]. Отмечается, что РВП характеризуют вербальную практику женщин, которые, в силу своего второстепенного статуса в «мужском социуме» (masculine society), избегают прямых утверждений, предпочитая включать в свою речь знаки смягчения силы утверждения, в том числе с помощью РВП [Pearson, West, Turner, 2005, p. 102-103]. Дж. Пирсон и ее коллеги при этом критично воспринимают результаты гендерно ориентированных экспериментов, указывая на необходимость более точной градации испытуемых по социально-ролевому и прагматическому статусам: «It may be wise to examine the context (informal conversation, business meeting, etc.) and the function of tag questions (i.e. whether the purpose is to draw out conversational partners, to request agreement or confirmation, to forestall opposition, etc.), rather than simply searching for their presence» [Pearson, West, Turner, 2005, p. 103]. В цитируемом исследовании указано, что в отдельных случаях РВП активно используются и в речи мужчин, однако авторы приведенных работ не видят главного - различия по синтаксической модели, интенциям, социально-ролевому фону в использовании РВП свидетельствуют об особой прагматике данных форм, связанной, в том числе, с национально-культурными конвенциями межличностного общения в англоговорящем (британском) социуме, не приветствующем, но допускающем ранжирование межличностной дистанции и статуса с помощью намеренного выбора языковых средств. Справедливости ради отметим, что идея о статусных, в том числе гендерных, предпочтениях в использовании РВП в устной речи, порой занимала исследователей, которые предпринимали попытки проверить или опровергнуть указанное предположение на корпусе устной речи английского языка в сравнении с другими языками (см. например: [Dubois, Crouch, 1975; Jovanonić, Pavlović , 2014; Weiss, 2015, etc.]).

Осмысление сведений о форме и прагматических функциях РВП позволили сфор- 
мировать гипотезу нашего исследования: в англоязычной коммуникативной практике особую функциональную значимость имеет тактика дискурсивной саморепрезентации, позволяющая выстраивать и регулировать межличностные отношения в ходе общения; одним из метаязыковых средств саморепрезентации личности в англоязычном межличностном общении является разделительное вопросительное предложение (tag clause), частотность обращения к которому зависит от статусной, возрастной и гендерной принадлежности дискурсивной личности. Для получения объективных данных о частотности обращения к формам РВП в англоязычной традиции общения, о социальной стратификации лиц, использующих их в своей речевой практике, был проведен прагмасоциолингвистический анализ на материале репрезентативного корпуса устной речи ${ }^{1}$.

\section{Корпусная методология}

\section{в социопрагматических исследованиях}

\section{коммуникации}

Корпусная методология, которая обеспечивает возможность анализа большого языкового / текстового материала, все чаще используется в дискурсивных исследованиях. Сопоставляя корпусно-ориентированный и дискурсивный анализ, В.Е. Чернявская указывает, что в интерпретативных концепциях корпусные методы связываются с достижением доказательности и преодолением тенденциозности и избирательности подходов [Чернявская, 2018, с. 32-33]. В последнее время на основе корпусных данных строятся когнитивно-дискурсивные модели, характеризующие смысловую организацию текстов единой жанровой принадлежности, выявляются воплощенные в дискурсе культурно-специфические смыслы, ценности, убеждения [Baker, 2006; Ilyinova, Kochetova, 2016; Gabrielatos, 2018; Partington, 2010]. Парадоксальная, на первый взгляд, связь между дискурсом как текучим, нечетким и размытым понятием и статистикой, научной дисциплиной, оперирующей четкими категориями, не воспринимается таковой, если принять определение дискурса как сложного социокультурного феномена, включающего различные способы трансляции смысла. В этом случае его статистический анализ ориентируется на смысловую составляющую слов, предложений, более сложных смысловых единств.

Методика анализа дискурса с использованием корпусного метода включает несколько этапов: 1) описание лингвистических данных корпуса, определение локальной и глобальной частотности языковых единиц, выявление ключевых слов, коллокаций и др.; 2) интерпретацию лингвистических данных корпуса с учетом ситуативно-дискурсивного аспекта, установление индексов и функций языковых структур в дискурсе; 3) объяснительность, отвечающую на вопросы о причинах употребления данных единиц и структур и характеризующую их обусловленность историческим, социальным, лингвокультурным контекстом.

В проведенном исследовании корпусный анализ английской устной речи был направлен на выявление социокультурных особенностей в использовании разделительных вопросов как способа дискурсивной саморепрезентации личности в ситуациях обыденного общения.

\section{Корпусный анализ}

\section{речевых актов саморепрезентации}

дискурсивной личности в англоязычном межличностном общении

Материал исследования. Корпусная лингвистика опирается, прежде всего, на использование репрезентативного и сбалансированного аннотированного лингвистического корпуса, снабженного программным обеспечением для извлечения и статистической обработки лингвистически релевантной информации [McEnery, Hardy, 2011]. Под корпусом текстов традиционно понимают «большой, представленный в машиночитаемом виде, унифицированный, структурированный, размеченный, филологически компетентный массив языковых данных, предназначенный для решения конкретных лингвистических задач» [Захаров, Богданова, 2011, с. 7].

Эмпирической базой исследования послужили репрезентативные и сбалансированные корпусы устной британской речи, первый из которых относится к концу 1980-х - началу 1990-х гг. и является частью Британского национального корпуса, созданного в начале 
1990-х гг. (далее - BNC1994), а второй содержит образцы британской устной речи, записанной в период с 2012 по 2016 г. (далее BNC2014). Данные двух корпусов являются сопоставимыми, различаются по временным критериям и позволяют проследить динамику в использовании изучаемых языковых единиц в соответствии с социально-демографическими, региональными и др. параметрами. Уточним, что объем корпуса устной речи ВNC1994 составляет 5014665 слов, это 153 скрипта устной речи 1408 респондентов, записанной в период с 1985 по 1993 г. Корпус BNC2014 образован из 11422622 слов, он содержит 1251 скрипт, представляющий фрагменты устной речи 672 респондентов. Метаданные корпуса включают возраст, пол, социально-экономический статус, уровень образования, регион проживания, диалект, что позволяет получить объективные данные о социальном статусе респондентов. Сведения о социальной стратификации в корпусе BNC2014 представлены в таблице 1. В корпусе BNC1994 отсутствует выделение подклассов А, В, D и Е, они сливаются в одну категорию.

Для дальнейшего анализа были поставлены следующие вопросы: 1) Отличается ли (и если да, то насколько) частотность использования разделительных вопросов в двух корпусах? 2) Различается ли (если да, то насколько) дистрибуция разделительных вопросов между корпусами? 3) Различается ли (если да, то насколько) социально-классовая дистрибуция разделительных вопросов между корпусами? 4) Различается ли (если да, то насколько) возрастная, социальная и гендерная дистрибуция разделительных вопросов между корпусами? 5) Как изменяется дискурсивная саморепрезентация личности в английском устном бытовом дискурсе?

Методология исследования. Для ответа на поставленные вопросы необходимо было определить частотность использования разделительных вопросов (РВП) в соответствии с социально-демографическими параметрами в сравниваемых корпусах и установить, ястатистически значимо ли это различие статистически значимым для каждого из исследуемых параметров. В целях выявления сходств и различий между двумя корпусами применялись статистические методы, в основе которых лежит нормализованная частотность, понимаемая как количество вхождений анализируемой

Таблица 1

Категоризация респондентов в соответствии с социально-экономическим статусом B BNC2014

\begin{tabular}{|c|c|c|c|}
\hline № & $\begin{array}{c}\text { ВNC2014 } \\
\text { Категории, выделяемые в соответствии } \\
\text { с социально-экономической классификацией } \\
\text { населения Бюро национальной статистики } \\
\text { (National Statistics Socio-economic Classification } \\
\text { (NS-SEC) }\end{array}$ & $\begin{array}{l}\text { Социальное } \\
\text { положение }\end{array}$ & $\begin{array}{c}\text { ВNC2014 } \\
\text { Категории, выделяемые в соответствии с данными } \\
\text { National Readership Survey Social Grade } \\
\text { classifications (NRS 2014) }\end{array}$ \\
\hline 1 & $\begin{array}{l}\text { Высшие руководящие должности в админист- } \\
\text { ративной и профессиональной деятельности }\end{array}$ & $\mathrm{A}$ & \multirow[t]{3}{*}{$\begin{array}{l}\text { Высшие руководящие должности в администра- } \\
\text { тивной и профессиональной деятельности }\end{array}$} \\
\hline 1.1 & $\begin{array}{l}\text { Крупные работодатели, менеджеры и адми- } \\
\text { нистративные работники высшего звена }\end{array}$ & & \\
\hline 1.2 & $\begin{array}{l}\text { Высшие должности в профессиональной дея- } \\
\text { тельности }\end{array}$ & & \\
\hline 2 & $\begin{array}{l}\text { Менеджеры, административные работники и } \\
\text { профессионалы младшего звена }\end{array}$ & $\mathrm{B}$ & $\begin{array}{l}\text { Менеджеры, административные работники и } \\
\text { профессионалы среднего звена }\end{array}$ \\
\hline 3 & Должности среднего звена & \multirow[t]{2}{*}{$\mathrm{C} 1$} & \multirow{2}{*}{$\begin{array}{l}\text { Супервайзеры, клерки, менеджеры, админист- } \\
\text { ративные работники и профессионалы младше- } \\
\text { го звена }\end{array}$} \\
\hline 4 & Мелкие работодатели и самозанятое население & & \\
\hline 5 & $\begin{array}{l}\text { Работники сферы технического обслужива- } \\
\text { ния и младшие супервайзеры }\end{array}$ & $\mathrm{C} 2$ & Квалифицированные рабочие \\
\hline 6 & $\begin{array}{l}\text { Должности, требующие выполнения рутин- } \\
\text { ных и самостоятельных действий }\end{array}$ & $\mathrm{D}$ & $\begin{array}{l}\text { Низкоквалифицированный и неквалифициро- } \\
\text { ванный персонал }\end{array}$ \\
\hline 7 & $\begin{array}{l}\text { Должности, требующие выполнения рутин- } \\
\text { ных действий }\end{array}$ & & \\
\hline 8 & $\begin{array}{l}\text { Неработающие и безработные длительный } \\
\text { период времени }\end{array}$ & \multirow[t]{2}{*}{$\mathrm{E}$} & \multirow{2}{*}{$\begin{array}{l}\text { Пенсионеры, низкоквалифицированные рабо- } \\
\text { чие и лица, живущие случайными заработками, } \\
\text { безработные, получающие пособие }\end{array}$} \\
\hline 9 & Студенты / иное & & \\
\hline
\end{tabular}


единицы на тысячу или миллион слов. В устном корпусе BNC2014 содержится 32500 случаев использования РВП (нормализованная частотность - 2845,23$)$, в корпусе устной речи BNC1994 - 16500 употреблений (нормализованная частотность - 3290,36$)$. Установление синхронной и диахронной вариативности для каждого из параметров стратификации (социального, возрастного, гендерного) проводилось с опорой на сравнение нормализованной частотности использования РВП представителями разных возрастных категорий в каждом из корпусов (диахронная вариативность), а также на частотность употребления РВП представителями разных социальных классов в пределах одного корпуса (синхронная вариативность). Сходным образом анализировалась гендерная специфика использования изучаемой конструкции. Для построения графиков и установления статистической значимости различий в употреблении разделительных вопросов между двумя корпусами с учетом социально-демографической стратификациимы обратились к онлайн-ресурсу Lancaster Stats Tools online ${ }^{2}$.

\section{Социолингвистический аспект}

\section{использования разделительных вопросов}

\section{в британской устной разговорной речи}

Установление характеристик по трем группам социолингвистических особенностей обращения к разделительным вопросам продолжим, представив данные корпусного анализа в виде таблиц, графиков, отражающих дистрибуцию использования конструкции РВП, так называемой ящичной диаграммы и статистических тестов.

В таблице 2 представлены данные о дистрибуции использования разделительных воп- росов в корпусах британской устной речи в зависимости от социальной принадлежности говорящих, извлеченные из корпусов ВNC1994 и ВNC2014.

Статистический анализ не выявил значимых различий в частотности употребления разделительного вопроса в зависимости от социальной принадлежности в диахронном и синхронном аспектах, отметим лишь уменьшение случаев использования моделей разделительных вопросов представителями низшего среднего класса (в частности, работниками сферы технического обслуживания, младшими супервайзерами) по параметру нормализованной частотности: 3335.75 (BNC 1994) и 1737.55 (BNC 2014). На рисунке 1 представлен график дистрибуции разделительных вопросов в зависимости от социальной принадлежности говорящих. Длинная линия обозначает медиану, а короткая линия - среднюю величину.

Различия наблюдаются в корпусе BNC1994 для низшего среднего класса C2 (работники сферы технического обслуживания и младшие супервайзеры), представители которого чаще использовали данную конструкцию. В корпусе BNC2014 отмечаются расхождения в классе D (низкоквалифицированный и неквалифицированный персонал) и C2 (квалифицированные рабочие). На графике данные классы находятся в диаметрально противоположных экстремальных точках. Как свидетельствуют данные, статистически значимой диахронной вариативности в социальном аспекте за прошедший период времени не наблюдается, в целом в речи различных социальных классов приблизительно в сходной пропорции отмечены разделительные вопросы. Однако в речи представителей средне-

Таблииа 2

Социально-стратифицированное использование разделительных вопросов в BNC1994 и BNC2014

\begin{tabular}{|c|c|c|c|c|c|c|}
\hline \multirow{2}{*}{$\begin{array}{c}\text { Параметры } \\
\text { Класс } \\
\end{array}$} & \multicolumn{2}{|c|}{$\begin{array}{l}\text { Абсолютная } \\
\text { частотность }\end{array}$} & \multicolumn{2}{|c|}{$\begin{array}{c}\text { Нормализованная } \\
\text { частотность }\end{array}$} & \multicolumn{2}{|c|}{$\begin{array}{c}\text { Размер корпуса } \\
\text { (млн слов) }\end{array}$} \\
\hline & BNC 1994 & BNC 2014 & BNC 1994 & BNC 2014 & BNC 1994 & BNC 2014 \\
\hline Высший (А) & 4161 & 5504 & 2530.71 & 2837.71 & 1,6 & 1.94 \\
\hline Высший (В) & - & 7794 & - & 2669.93 & 1.6 & 2.92 \\
\hline Высший средний (C1) & 4028 & 4422 & 3071.74 & 2927.77 & 1,3 & 1.51 \\
\hline Средний (C2) & 4230 & 307 & 3335.75 & 1737.55 & 1,2 & 0.18 \\
\hline Рабочий класс (D) & 2305 & 2268 & 3091.00 & 3574.16 & 0,7 & 0.63 \\
\hline Рабочий класс (Е) & - & 11384 & - & 2952.79 & 0,7 & 0.39 \\
\hline
\end{tabular}


Е.Ю. Ильинова, Л.А. Кочетова. Дискурсивная саморепрезентация личности

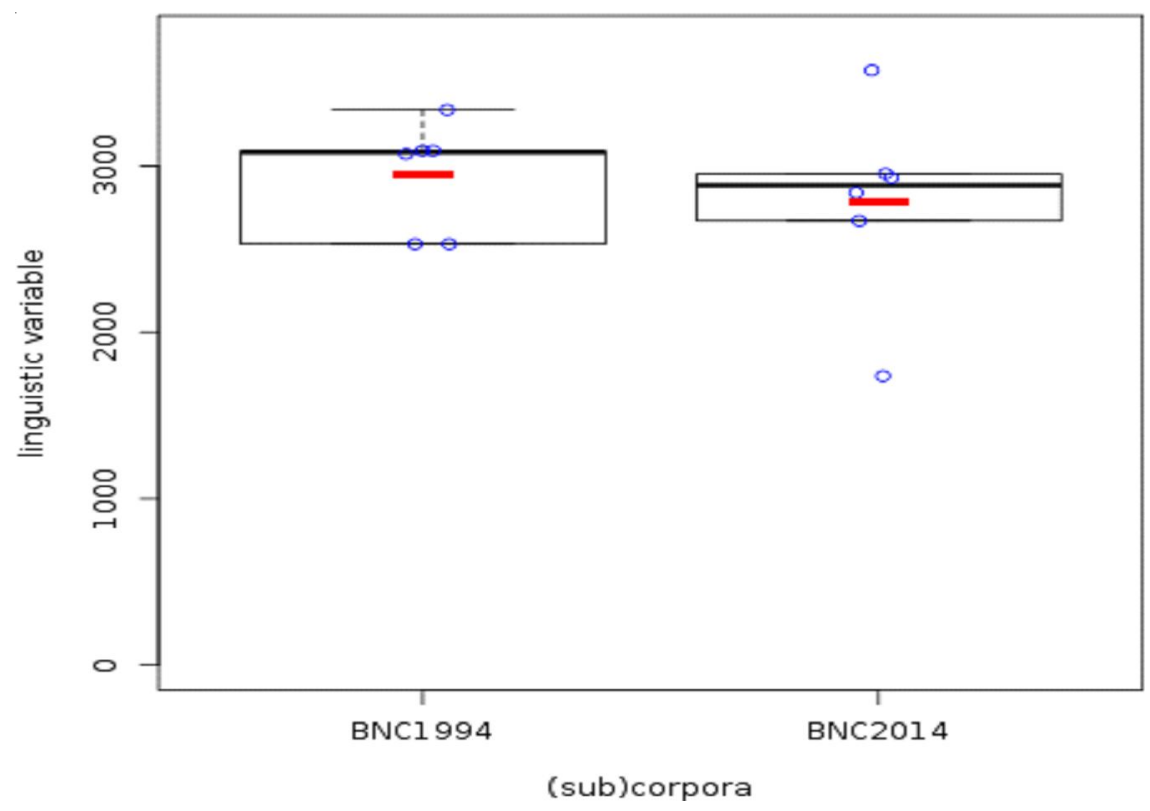

Рис. 1. Дистрибуция разделительных вопросов в зависимости от социальной принадлежности говорящих

го класса отмечается существенное снижение численности разделительных конструкций за изученный период, что свидетельствует о появлении признаков изменений коммуникативных конвенций в формах дискурсивной саморепрезентации в речи представителей данного социального слоя.

Анализ корпусных данных об использовании конструкции РВП в речи представителей различных возрастных групп позволил выявить значимую диахронную и синхронную вариативность. Как показывает таблица 3, в целом отмечается тенденция к снижению числа употреблений РВП в устной речи более молодыми респондентами. Об этом свидетельствуют данные о частотности, которые для данной таблицы были извлечены для идентичных возрастных групп двух корпусов, принадлежащих различным времен- ным периодам. Наибольшие различия наблюдаются для самой молодой возрастной группы, наименьшие - для респондентов в возрасте от 35 до 44 лет.

Как показывает статистический анализ, расхождение частотности использования разделительных вопросов представителями самой младшей и самой старшей возрастных групп в корпусе BNC2014 обладает статистической значимостью, так как стандартная девиация имеет величину 2 188.23, что превышает среднее значение, которое составляет 1772.69. В корпусе BNC1994 статистически значимых различий между сопоставляемыми группами не наблюдается, так как стандартная девиация составляет 936.80 при среднем значении нормализованной частотности 2734.42.

На основании корпусных данных была построена диаграмма, позволяющая нагляд-

Стратифицированное использование разделительных вопросов по возрастным группам в ВNC1994 и ВNC2014

\begin{tabular}{|c|c|c|c|c|c|c|}
\hline Параметры & \multicolumn{2}{|c|}{$\begin{array}{c}\text { Абсолютная } \\
\text { частотность }\end{array}$} & \multicolumn{2}{c|}{$\begin{array}{c}\text { Нормализованная } \\
\text { частотност }\end{array}$} & \multicolumn{2}{c|}{$\begin{array}{c}\text { Размер корпуса } \\
\text { (млн слов) }\end{array}$} \\
\hline Bозраст & ВNC 1994 & BNC 2014 & BNC 1994 & BNC 2014 & BNC 1994 & ВNC 2014 \\
\hline $\mathbf{0 - 1 4}$ & 667 & 318 & 2070.00 & 1028.54 & 0.32 & 0,30 \\
\hline $\mathbf{1 5}-\mathbf{2 4}$ & 1943 & 5265 & 2443.26 & 1895.41 & 0.79 & 2,77 \\
\hline $\mathbf{2 5}-\mathbf{3 4}$ & 3029 & 4106 & 2994,94 & 2530.95 & 1.01 & 1,62 \\
\hline $\mathbf{3 5 - 4 4}$ & 3056 & 4306 & 3051.29 & 3120.78 & 1,00 & 1,37 \\
\hline $\mathbf{4 5 - 5 9}$ & 3568 & 7586 & 3134.14 & 3456.88 & 1,13 & 2,19 \\
\hline $\mathbf{6 0 +}$ & 2532 & 7818 & 3394.84 & 4236.08 & 0,74 & 1,84 \\
\hline
\end{tabular}


но продемонстрировать изменения в потребности обращения к разделительным вопросам с учетом возрастного параметра. На рисунке 2 представлен график дистрибуции использования разделительных вопросов в зависимости от возрастной принадлежности говорящих. Наблюдается устойчивая тенденция к уменьшению использования разделительных вопросов в британском устном разговорном дискурсе, о чем свидетельствуют точки экстремумов на обоих графиках.

Анализ гендерной маркированности респондентов в случаях использования ими разделительных вопросов в устной речи указал на совпадения в сравниваемых корпусах (табл. 4).

Данные о частотности обращения к РВП в гендерном аспекте, представленные в таблице 4, не показывают статистически значимых различий в диахронном и синхронном аспектах. Таким образом, выдвигаемые в указанных выше работах зарубежных исследователей предположения о связи разделительного вопроса с особенностями женской речи оказываются несостоятельными, что подтверждается данными корпуса.

\section{Выводы}

Исследование речевых форм общения методами корпусной лингвистики позволило верифицировать авторскую научную гипотезу о коммуникативно-прагматической значимости разделительного вопроса, о социолингвистических особенностях обращения к нему в англоязычном устном общении, о динамике его использования в диахроническом аспекте.

Корпусный подход к анализу репрезентативного материала, принадлежащего двум хронологически близким срезам в британском корпусе устной речи, позволил установить социолингвистическую синхронную вариативность в использовании разделительных вопросов с учетом фактора социальной стратификации говорящих и проследить динамику обращения к ним по социально-демографическому, возрастному, гендерному параметрам.

Нами выявлено изменение в дискурсивном поведении представителей низшего среднего класса, в речи которых наблюдается тенденция к уменьшению частотности

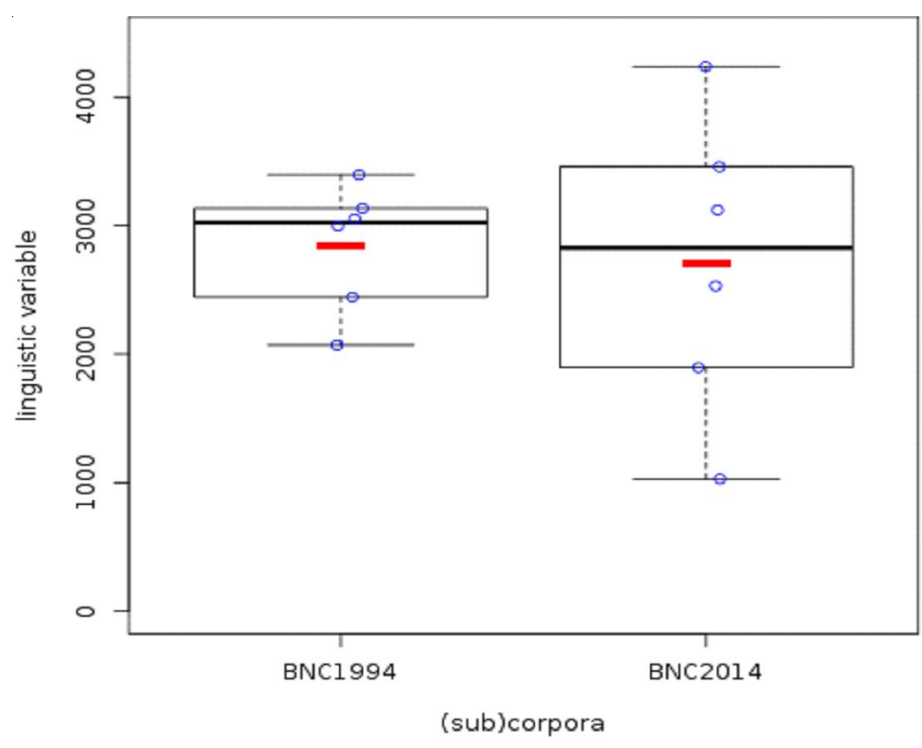

Рис. 2. Дистрибуция разделительных вопросов в зависимости от возрастной принадлежности говорящих

Таблииа 4

Гендерный аспект использования разделительных вопросов в BNC1994 и BNC2014

\begin{tabular}{|l|c|c|c|c|c|c|}
\hline Параметры & \multicolumn{2}{|c|}{$\begin{array}{c}\text { Абсолютная } \\
\text { частотность }\end{array}$} & \multicolumn{2}{c|}{$\begin{array}{c}\text { Нормализованная } \\
\text { частотость }\end{array}$} & \multicolumn{2}{c|}{$\begin{array}{c}\text { Размер корпуса } \\
\text { (млн слов) }\end{array}$} \\
\hline Гендер & BNC 1994 & BNC 2014 & BNC 1994 & BNC 2014 & BNC 1994 & BNC 2014 \\
\hline Женщины & 8597 & 19891 & 2998.01 & 2812.54 & 2,94 & 7,01 \\
\hline Мужчины & 6159 & 12720 & 2923.63 & 2924.82 & 2,05 & 4,34 \\
\hline
\end{tabular}


употребления разделительных вопросов. Анализ показал значительные количественные колебания в использовании РВП разными возрастными группами при сравнении корпусов устной речи 1994 и 2014 гг, , сопоставление частотности РВП в речи молодых и более старших возрастных групп свидетельствует о тенденции к уменьшению использования данного типа предложений. Существенных различий в употреблении РВП в гендерном аспекте в обоих корпусах выявлено не было, что опровергает ранее выдвигавшийся тезис о преобладании разделительных вопросов в женской речи как некатегоричного знака неуверенности в себе. Необходимо отметить, что полученные в результате корпусного анализа данные о социолингвистической вариативности дискурсивной саморепрезентации с помощью разделительного вопроса в различных социальных и возрастных группах и диахронных изменениях в его использовании не опровергают этнокультурной значимости данной синтаксической модели для британской коммуникативной традиции. В зависимости от прагматических условий коммуникации и социального статуса говорящих англичанам удается реализовать разные прагматические задачи - от намерения установить требуемую межличностную дистанцию, указать на возможность / невозможность дискуссии или дальнейшего обсуждения вопроса, попытки выразить поддержку до (намеренной или ненамеренной) демонстрации подчиненной позиции, согласия, страха быть непонятым или отвергнутым.

Перспективным представляется продолжение данного исследования в аспекте изучения коммуникативной ценности разделительного вопроса в англоязычном общении с учетом возрастных и социально-статусных параметров.

\section{ПРИМЕЧАНИЯ}

${ }^{1}$ При анализе языкового материала использовались данные из British National Corpus. URL: http://www.natcorp.ox.ac.uk.

${ }^{2}$ В исследовании использовались статистические инструменты Lancaster Stats Tools online. URL: http://corpora.lancs.ac.uk/stats.

\section{СПИСОК ЛИТЕРАТУРЫ}

Волкова О. С., 2014. Коммуникативная провокация как стратегия деструктивного поведения в бытовом конфликте // Вестник Волгоградского государственного университета. Серия 2, Языкознание. №5 (24). C. 49-55. DOI: http://dx.doi.org/10.15688/ jvolsu2.2014.5.6.

Захаров В. П., Богданова С. Ю., 2011. Корпусная лингвистика. Иркутск : ИГЛУ. 161 с.

Иванова И. П., Бурлакова В. В., Почепцов Г. Г., 1981. Теоретическая грамматика современного английского языка. М. : Высш. школа. 285 с.

Ирисханова О. К., 2009. Речевые акты уклонения: на стыке когнитологии и прагматики // Горизонты современной лингвистики: традиции и новаторство. М. : Языки славянских культур. С. 684-693.

Историческая динамика дискурсивных практик, 2017. Историческая динамика дискурсивных практик : колл. монография / науч. ред. Л. А. Кочетова, Е. Ю. Ильинова. Волгоград : Изд-во ВолГУ. $228 \mathrm{c.}$

Карасик В. И., 2014. Языковое проявление личности. Волгоград : Парадигма. 450 с.

Кубрякова Е. С., 2004. Язык и знание : На пути получения знаний о языке : Части речи с когнитивной точки зрения. Роль языка в познании мира. М. : Языки славянской культуры. 560 с.

Ларина Т. В., 2009. Категория вежливости и стиль коммуникации: сопоставление английских и русских лингвокультурных традиций. М. : Рукописные памятники Древней Руси. 512 с.

Литвинова В. А., 2015. Коммуникативно-прагматическая специфика английского этического извинения // Вестник Волгоградского государственного университета. Серия 2, Языкознание. - Т. 14, № 5. - C. 109-113. - DOI: http:// dx.doi.org/10.15688/jvolsu2.2015.5.12.

Матвеева Г. Г., Ленец А. В., Петрова Е. И., 2013. Основы прагмалингвистики. М. : Флинта : Наука. 232 с.

Моторина Н. В., 2013. Лингвокультурный скрипт «посещение ресторана» в английском коммуникативном поведении» // Известия Волгоградского государственного педагогического университета. № 6 (81). С. 24-27.

Почтарь Е.И., 2016. Прагматические основы нарушения коммуникативного кодекса в современном дискурсе // Вестник Волгоградского государственного университета. Серия 2, Языкознание. 2014. № 3 (22). С. 129-134. DOI: http://dx.doi.org/jvolsu2.2014.3.17.

Чернявская В. Е., 2018. Дискурсивный анализ и корпусные методы: необходимое доказательное звено? Объяснительные возможности каче- 
ственных и количественных подходов // Вопросы когнитивной лингвистики. № 2 (55). C. 31-37.

Atai M., Sadr L., 2008. A cross-cultural genre study on hedging devices in discussion section of applied linguistics research articles // Teaching English Language and Literature Society of Iran. Vol. 2, no. 7. P. 1-22. URL: http://www.sid.ir/En/Journal/ ViewPaper.aspx?ID=162198 (date of access: 24.05.2018).

Baker P., 2006. Using Corpora in Discourse Analysis. London; New York : Continuum. 198 p.

Boncea I. J., 2013. Hedging Patterns Used as Mitigation and Politeness Strategies // Annals of the University ofCraiova. Series: Philology. English. Vol. 2. P. 7-23. URL: http://cis01.central.ucv.ro/litere/activ_st/ anale_engleza/Annals_vol2_2013_Limba.pdf (date of access: 23.05.2018).

Brezina V., 2018. Statistical choices in corpus-based discourse analysis // Corpus Approaches to Discourse / ed. by Ch. Taylor, A. Marchi. Oxford : Routledge. P. 259-280.

Downing A., 2015. English Grammar : a university course. $3^{\text {rd }}$ ed. N.Y. : Routledge. 652 p.

Dubois B. L., Crouch I., 1975. The Question of Tag Questions in Women's Speech: They Don't Really Use More of Them, Do They? // Language in Society. Vol. 4, no. 3. P. 289-294.

English Language..., 2018. English Language: Description, Variation and Context / ed. by J. V. Culpeper, P. Kerswill, R. Wodak, T. McEnery, F. Katamba. $2^{\text {nd }}$ ed. London : Palgrave Macmillan. $686 \mathrm{p}$.

Fox Kate, 2004. Watching the English. The Hidden Rules of English Behavior. London : Hodder. $424 \mathrm{p}$.

Gabrielatos C., 2018. Keyness analysis: nature, metrics and techniques // Corpus Approaches to Discourse / ed. by Ch. Taylor, A. Marchi. Oxford : Routledge. P. 225-258.

Jovanović V. Ž., Pavlović V., 2014. The Use of Question Tags with Male and Female Speakers of English and Serbian // Jezici i kulture u vremenu i prostoru III. Chapter: XLVI/ ed. by S. Gudurić, M. Stefanović. P. 491-504. URL: https:// www.researchgate.net/publication/298214908 (date of access: 22.04.2018).

Ilyinova E.Yu., Kochetova L.A., 2016. Diachronic Perspective in Text and Discourse Studies: Review of Approaches // Вестник Волгоградского государственного университета. Сер. 2, Языкознание. - Т. 15, № 4. - С. 18-25. DOI: https://doi.org/10.15688/jvolsu2.2016.4.2.

Lakoff R., 1972. The Pragmatics of Modality // Papers from the Eighth Regional Meeting. Chicago : Chicago Linguistic Society. P. 229-246.
Lakoff,R., 1975. Language and Woman's Place. New York : Harper and Row. 328 p.

McEnery T., Hardy A., 2011. Corpus Linguistics: Method, Theory and Practice. Cambridge : Cambridge University Press. 301 p.

Partington A., 2010. Modern diachronic corpus-assisted discourse studies on UK newspapers: an overview of the project // Corpora. Vol. 5, iss. 2. P. 83-108.

Pearson J. C., West R., Turner L. H., 2005. Gender and Communication. N.Y. : McGraw-Hill. 285 p.

Plotnikova S. N., 2013. Cognitive Scenario of Discourse of Deception // Journal of Siberian Federal University. Humanities \& Social Sciences, vol. 6, no. 4 , pp. 589-602.

Quirk R. et al., 1985. Quirk R., Greenbaum S., Leech G., SvartvikJ. A Comprehensive Grammar of the English Language. London : Longman. 1779 p.

Spencer-Oatey H., 2000. Rapport management: a framework for analysis // Culturally Speaking : Managing Rapport Through Talk Across Cultures. London; New York : Continuum. P. 11-46.

Stubbs M., 1983. Discourse Analysis: The Sociolinguistic Analysis of Natural Language. Chicago : The University of Chicago Press. 279 p.

Weiss S., 2015. 4 Verbal Habits Of Women That Don't Mean What You Think They Do, Because The Policing Of Women's Language Needs To Stop. Bustle Digital Group. URL: https://www.bustle.com/articles/117516-4verbalhabits-of-women-that-dont-meanwhat-you-think-they-do-because-thepolicing (date of access: 7.03.2018).

Yang Y., 2013. Exploring linguistic and cultural variations in the use of hedges in English and Chinese scientific discourse // Journal of Pragmatics. Vol. 50 (1). P. 23-36. DOI: 10.1016/ j.pragma.2013.01.008.

Yule G., 2006. The Study of Language : An Introduction. Cambridge : Cambridge University Press. 273 p.

\section{REFERENCES}

Volkova O.S., 2014. Communicative provocation as a strategy of destructive behavior in everyday conflict. Vestnik Volgogradskogo gosudarstvennogo universiteta. Seriya 2. Yazykoznanie [Science Journal of Volgograd State University. Linguistics], no. 5 (24), pp. 49-55. DOI: http://dx.doi.org/10.15688/ jvolsu2.2014.5.6.

Zakharov V.P., Bogdanova S.Yu., 2011. Corpus Linguistics. Irkutsk, IGLU Publ. 161 p.

Ivanova I.P., Burlakova V.V., Pocheptsov G.G., 1981. Theory of modern English grammar. Moscow, Vysshaya shkola Publ., 1981.285 p. 
Iriskhanova O.K., 2009. Speech Acts of Evasion: the border line between cognitive and pragmatic sciences. Gorizonty sovremennoy lingvistiki: traditsii i novatorstvo. Moscow, Yazyki slavyanskikh kultur Publ., pp. 684-693.

Kochetova L.A., Ilyinova E.Yu., eds., 2017. On historical dynamics of discourse practice. Volgograd, Izd-vo VolGU. 228 p.

Karasik V.I., 2014. Linguistic representation of personality. Volgograd, Paradigma Publ. 450 p.

Kubryakova E.S., 2004. Language and knowledge: on the way of getting knowledge about language: parts of speech in cognitive aspect. The role of language in cognition. Moscow, Yazyki slavyanskoy kultury Publ. 560 p.

Larina T.V., 2009. The category of politeness and communication style: comparison of English and Russian linguocultural traditions. Moscow, Rukopisnye pamyatniki Drevney Rusi Publ. 512 p.

Litvinova V. A., 2015. Communicative and Pragmatical Specificity of the English Ethical Apology. Vestnik Volgogradskogo gosudarstvennogo universiteta. Seriya 2, Yazykoznanie [Science Journal of Volgograd State University. Linguistics], vol. 5, no. 29, pp. 109-113. DOI: http://dx.doi.org/10.15688/jvolsu2.2015.5.12.

Matveeva G.G., Lenets A.V., Petrova E.I., 2013. Basics of pragmatic lingusitics. Moscow, Flinta; Nauka Publ. 232 p.

Motorina N.V., 2013. Linguocultural script 'at the restaurant' in the English communicative behavior. Izvestiya Volgogradskogo gosudarstvennogo pedagogicheskogo universiteta [Izvestia of the Volgograd State Pedagogical University], no. 6 (81), pp. 24-27.

Pochtar E.I., 2014. Pragmatic foundations of communication code failure in present-day discourse. Vestnik Volgogradskogo gosudarstvennogo universiteta. Seriya 2, Yazykoznanie [Science Journal of Volgograd State University. Linguistics], no. 3 (22), pp. 129 134. DOI: http://dx.doi.org/jvolsu2.2014.3.17.

Chernyavskaya V.E., 2018. Discourse analysis and corpus methods: missing evidence-based link? Towards Qualitative and Quantitative Approaches in Language Studies. Voprosy kognitivnoy lingvistiki [Issues of Cognitive Linguistics], no. 2(55), pp. 31-37. DOI: 10.20916/ 1812-3228-2018-2-31-37.

Atai M., Sadr L., 2008. A cross-cultural genre study on hedging devices in discussion section of applied linguistics research articles. Teaching English Language and Literature Society of Iran, vol. 2, no. 7, pp. 1-22. URL: http://www.sid.ir/En/ Journal/ViewPaper.aspx?ID=162198. (accessed 24 May 2018).
Baker P., 2006. Using Corpora in Discourse Analysis. London; New York, Continuum. 198 p.

Boncea I.J., 2013. Hedging patterns used as mitigation and politeness strategies. Annals of the University of Craiova. Series: Philology. English, vol. 2, pp. 7-23. URL: http://cis01.central.ucv.ro/ litere/activ_st/anale_engleza/Annals_vol2 2013_Limba.pdf. (accessed 23 May 2018).

Brezina V., 2018. Statistical choices in corpus-based discourse analysis. Taylor Ch., Marchi A., (eds.) Corpus Approaches to Discourse. Oxford, Routledge, pp. 259-280.

Downing A., 2015. English Grammar: a university course. New York, Routledge. 652 p.

Dubois B.L., Crouch I., 1975. The question of tag questions in women's speech: they don't really use more of them, do they? Language in Society, vol. 4, no. 3, pp. 289-294.

Culpeper J.V., Kerswill P., Wodak R., McEnery T., Katamba F., (eds.), 2018. English language: description, variation and context. London, Palgrave Macmillan. 686 p.

Fox K., 2004. Watching the English. The hidden rules of English behavior. London, Hodder. 424 p.

Gabrielatos C., 2018. Keyness analysis: nature, metrics and techniques. Taylor Ch., Marchi A. (eds.) Corpus Approaches to Discourse. Oxford, Routledge, pp. 225-258.

Jovanović V. Ž., Pavlović V., 2014. The use of question tags with male and female speakers of English and Serbian. S. Gudurić, M. Stefanović. (eds.) Jezici i kulture u vremenu i prostoru III. Chapter: XLVI. Filozofski fakultet Univerzitet u Novom Sadu. pp. 491-504. URL: https://www.researchgate.net/ publication/298214908 (accessed 22 April 2018).

Ilyinova E.Yu., Kochetova L.A., 2016. Diachronic Perspective in Text and Discourse Studies: Review of Approaches. Vestnik Volgogradskogo gosudarstvennogo universiteta. Seriya 2, Yazykoznanie [Science Journal of Volgograd State University. Linguistics], vol. 15, no. 4, pp. 1825. DOI: https://doi.org/10.15688/jvolsu2.2016.4.2.

Lakoff R., 1972. The Pragmatics of Modality. Papers from the Eighth Regional Meeting. Chicago, Chicago Linguistic Society, pp. 229-246.

Lakoff R., 1975. Language and Woman's Place. New York, Harper and Row. 328 p.

McEnery T., Hardy A., 2011. Corpus Linguistics: Method, Theory and Practice. Cambridge, Cambridge University Press. 301 p.

Partington A., 2010. Modern diachronic corpusassisted discourse studies on UK newspapers: an overview of the project. Corpora, vol. 5, iss. 2, pp. 83-108.

Pearson J.C., West R., Turner L.H., 2005. Gender and Communication. New York, McGraw-Hill. 285 p. 
Plotnikova S. N., 2013. Cognitive Scenario of Discourse of Deception // Journal of Siberian Federal University. Humanities \& Social Sciences, vol. 6, no. 4, pp. 589-602.

Quirk R., Greenbaum S., Leech G., Svartvik J., et al., 1985. A Comprehensive Grammar of the English Language. London, Longman. 1779 p.

Spencer-OateyH., 2000. Rapportmanagement: a framework for analysis. Culturally Speaking: Managing Rapport Through Talk Across Cultures. London; NewYork, Continuum, pp. 11-46.

Stubbs M., 1983. Discourse analysis: The sociolinguistic analysis of natural language. Chicago, The University of Chicago Press. 279 p.
Weiss S., 2015. 4 verbal habits of women that don't mean what you think they do, because the policing of women's language needs to stop. URL: https://www.bustle.com/articles/117516-4verbalhabits-of-women-that-dont-mean-whatyou-think-they-do-because-the-policing (accessed 7 March 2018).

Yang Y., 2013. Exploring linguistic and cultural variations in the use of hedges in English and Chinese scientific discourse. Journal of Pragmatics, vol. 50 (1), pp. 23-36. DOI: 10.1016/ j.pragma.2013.01.008.

Yule G., 2006. The study of language: An introduction. Cambridge, Cambridge University Press. 273 p.

\section{Information about the Authors}

Elena Yu. Ilyinova, Doctor of Sciences (Philology), Professor of Department of English Philology, Volgograd State University, Prosp. Universitetsky, 100, 400062 Volgograd, Russia, ilynov@volsu.ru, english_philolog@mail.ru, http://orcid.org/0000-0002-3310-4020

Larisa A. Kochetova, Doctor of Sciences (Philology), Associate Professor, Head of Department of English Philology, Volgograd State University, Prosp. Universitetsky, 100, 400062 Volgograd, Russia, kochetova@volsu.ru, english_philolog@mail.ru, http://orcid.org/0000-0002-5278-7373

\section{Информация об авторах}

Елена Юрьевна Ильинова, доктор филологических наук, профессор кафедры английской филологии, Волгоградский государственный университет, просп. Университетский, 100, 400062 г. Волгоград, Россия, ilynov@volsu.ru, english_philolog@mail.ru, http://orcid.org/0000- 0002-3310-4020

Лариса Анатольевна Кочетова, доктор филологических наук, доцент, заведующая кафедрой английской филологии, Волгоградский государственный университет, просп. Университетский, 100, 400062 г. Волгоград, Россия, kochetova@volsu.ru, english_philolog@mail.ru, http://orcid.org/0000-0002-5278-7373 